\title{
Hematología y COVID-19
}

\section{Hematology and COVID-19}

\author{
Óscar Hernández-Zamudio* \\ Servicio de Hematología, Hospital General "Dr. Rafael Pascacio Gambio", Tuxtla Gutierréz, Chiapas
}

El mundo actualmente vive una pandemia de proporciones inusitadas ocasionada por el coronavirus 2 del síndrome respiratorio agudo grave (SARS-CoV-2), que produce la enfermedad por coronavirus 2019 (COVID-19). Desde la última pandemia por la mal llamada "gripe española» en 1926, la comunidad médica ha entrado en una vorágine de información científica de diferentes niveles de evidencia científica, aunado a ello, los medios oficiales de información y las redes sociales han jugado un papel importante en difundir noticias que no necesariamente cumplen con la rigidez científica. Lo anterior ha conllevado que el equipo de salud se encuentre sometido a una influencia masiva de información sobre esta pandemia.

EI SARS-CoV-2 surgió en diciembre del 2019 en la provincia de Wuhan, China, y desde entonces se ha diseminado por todo el mundo contagiando a millones de personas, sin importar nacionalidad ni origen étnico. En la mayoría de los países la pandemia ha desbordado los sistemas de salud por el desconocimiento del impacto que traería el virus. Cada país ha intentado mitigar el número de contagios, así como la mortalidad y complicaciones asociadas, sin embargo, esto ha representado un reto en el tratamiento de los pacientes debido a que no existe un fármaco que sea eficaz para controlar la infección y sus complicaciones. Las terapias que se tienen son coadyuvantes en el manejo de los pacientes, tal es el caso de colchicina, la dexametasona o las heparinas de peso molecular bajo.

Por otro lado, el virus afecta a múltiples sistemas del organismo. De hecho, desde los primeros informes publicados en China y posteriormente en Europa se identificó la afectación multisistémica del virus, incluso los primeros datos informados fueron: trastornos de la coagulación, variación en los leucocitos y elevación de ferritina, entre otras modificaciones hematológicas. Estas alteraciones hematológicas generaron muchas expectativas sobre el posible uso de algunos blancos moleculares capaces de inhibir vías metabólicas dentro de las células, de hecho, al momento actual continúan los estudios clínicos sobre ello.

Las alteraciones hematológicas más importantes que han persistido en los estudios de investigación sobre los mecanismos que desencadenan el daño pulmonar y sistémico son las modificaciones en los mecanismos de la hemostasia con el daño endotelial, la hiperactivación de plaquetas y de los procesos de coagulación, además de los mecanismos de regulación antitrombótica y fibrinolítica. Lo anterior, solo para ejemplificar las alteraciones hematológicas presentes en este tipo de infección. Por ello surge la necesidad de difundir el conocimiento mediante un suplemento especial dedicado a hematología y COVID-19.

A la Agrupación Mexicana para el estudio de la Hematología, la persistencia de la pandemia por el virus SARS-CoV-2 (que ha modificado nuestro vivir tanto personal como profesional) nos ha permitido vislumbrar maneras diferentes de actualizar el manejo clínico de los pacientes hematológicos, la mayoría de alto riesgo. Se ha solicitado apoyo a los grupos de trabajo de nuestra agrupación, para que con su experiencia podamos, por medio de plataformas, implementar recomendaciones que favorezcan nuestra actividad clínica.
Correspondencia:

*Óscar Hernández-Zamudio

E-mail: jamescamouflage@yahoo.com
Gac Med Mex. 2021;157(Supl 3):S1-S2 $\begin{array}{lr}\text { Fecha de aceptación: 09-02-2021 } & \text { Disponible en PubMed } \\ \text { DOI: } 10.24875 / G M M . M 21000464 & \text { www.gacetamedicademexico.com }\end{array}$ Fecha de aceptación: 09-02-2021 $\quad \begin{array}{r}\text { Disponible en PubMed } \\ \text { DOI: } 10.24875 / G M M . M 21000464\end{array}$ www.gacetamedicademexico.com A.C. Publicado por Permanyer. Este es un artículo open access bajo la licencia CC BY-NC-ND (http://creativecommons.org/licenses/by-nc-nd/4.0/). 
En este suplemento se publican temas donde se plantea el impacto del SARS-CoV-2 en bancos de sangre, servicios de transfusión, uso de plasma convaleciente, síndromes mielodisplásicos, leucemias agudas y crónicas, linfomas, mieloma múltiple, hemostasia y trombosis, contando con expertos mexicanos, quienes con base en su experiencia clínica, explican y recomiendan conductas que seguir en cada situación clínica.

Dr. Óscar Hernández-Zamudio

Presidente 